\title{
Factors associated with the development of vasculitis in rheumatoid arthritis: results of a case-control study
}

Alexandre E Voskuyl, Aeilko H Zwinderman, Marie Louise Westedt, Jan P Vandenbroucke, Ferdinand C Breedveld, Johanna M W Hazes

\begin{abstract}
Objective-To investigate those characteristics of patients with rheumatoid arthritis (RA) that are associated with the development of rheumatoid vasculitis (RV).

Methods-Demographic and clinical data of 69 patients who had been diagnosed as having RV were compared with those of 138 contemporaneous control patients with RA who were not suspected to have vasculitis. Vasculitis was confirmed histologically in $96 \%$ of the subjects with RV.

Results-Variables associated with the development of RV were: 1) male gender, presence of increased serum concentrations of rheumatoid factor, joint erosions, subcutaneous nodules, number of disease modifying antirheumatic drugs previously prescribed, treatment (ever) with D-penicillamine or azathioprine; 2 ) presence of nail fold lesions and any other extraarticular feature one year before the time of diagnosis of $R V$; 3) treatment with corticosteroids at the time of diagnosis of RV.

Conclusions-The development of RV is associated with male gender, extraarticular features, and a severe course of RA as indicated by the presence of joint destruction and need for intensive treatment with antirheumatic drugs. The strongest association was found with the presence of increased concentrations of rheumatoid factor.
\end{abstract}

(Ann Rheum Dis 1996; 55: 190-192)

Rheumatoid arthritis (RA) can be complicated by vascular inflammation that involves small and medium sized vessels. Skin rash, cutaneous ulcerations, constitutional symptoms, neuropathy, and abnormalities of visceral organs may occur in patients with rheumatoid vasculitis (RV)..$^{1-4}$ The presence of increased serum concentrations of rheumatoid factor and extra-articular features were observed in a large majority of patients with RV, and have been suggested to be associated with development of the condition $;^{2-6}$ corticosteroid treatment has also been suggested to be associated with the development of RV. ${ }^{7}$ The present controlled study aimed to identify those demographic characteristics and clinical variables of $R A$ patients that precede the development of RV.

\section{Patients and methods}

PATIENTS

The study was designed as a matched casecontrol study. All patients met the 1958 American Rheumatism Association criteria for classic or definite $\mathrm{RA}^{8}$ and attended the Rheumatology Department of Leiden University Hospital between January 1980 and December 1993.

$R V$ cases-All RA patients who had been diagnosed during the period $1980-93$ as having RV were identified by review of hospital diagnosis registers. All but two, for whom the medical charts were missing, were included in the study $(n=69)$. Forty eight were identified by review of outpatient clinic registers, and 21 additional cases were identified by review of inpatient clinic registers and a register on biopsy results identifying vasculitis. Tissue biopsying had been performed in all RV cases and histological evidence for vasculitis was found in all but three of them; in those three, no alternative explanation for the organ lesions could be found.

$R A$ controls - The RA controls were matched for the year in which the diagnosis of RV was made in the paired RV case: for each RV case, two RA controls were chosen randomly from a hospital register of all RA patients visiting the outpatient clinic in the same year that the diagnosis of $\mathrm{RV}$ was made in the corresponding case. Vasculitis was assumed to be absent if there was no suspicion of vasculitis one year before the index date, which was the date on which the diagnosis of vasculitis was made in the corresponding RV case. The absence of $\widetilde{N}$ vasculitis was ascertained in all RA controls in $N$ three ways: by detailed investigation of all N medical records; by checking the diagnostic registers of in- and outpatients; and by checking a computerised hospital register of all patients who had undergone tissue biopsy because of suspicion of vasculitis.

\section{METHODS}

The demographic and clinical data of RV cases and RA controls were obtained from in- and outpatient clinic medical charts in a standardised way, according to a defined procedure. The following variables were obtained $\underset{?}{\partial}$ up to the index date and were considered as potentially associated with the development of $\mathrm{RV}$ : gender, age, duration of RA, presence of increased RF concentrations, joint erosions, subcutaneous nodules, extra-articular features, \\ Rheumatology,
}

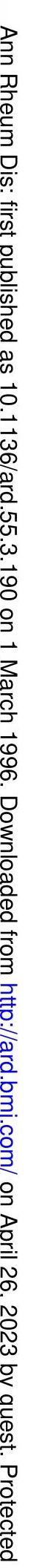


treatment with disease modifying antirheumatic drugs (DMARDs) or corticosteroids.

\section{STATISTICAL ANALYSIS}

Comparisons of demographic and clinical data were made between RV cases and RA controls using the $\chi^{2}$ test and the Mann-Whitney $U$ test, where appropriate. For variables potentially associated with the development of $\mathrm{RV}$, the crude and adjusted odds ratios with $95 \%$ confidence interval were calculated with conditional logistic regression analysis, in which each RV case and its two matched RA controls formed a separate stratum. In the analysis, data on all variables were used as scored at the index date, except for the variable nail fold lesions and any of the other extraarticular features (pericarditis, pleuritis, (epi)scleritis, distal sensory neuropathy, Felty's syndrome); data on these variables were used as scored one year before the index date, because the occurrence of extra-articular features at the time of the index date could have been the motivating influence for a specific diagnostic strategy. Extra-articular features that formed part of the RV diagnosis were not included in the analysis; they comprised mononeuritis multiplex, deep cutaneous ulcers, gangrene, ischaemic bowel disease, necrotising glomerulonephritis, ulcerative scleritis, petechiae, and purpura.

\begin{abstract}
Results
Table 1 shows the basic characteristics of the study population. When compared with RA controls, RV cases were more often men, and more frequently had increased RF concentrations, joint erosions, and subcutaneous nodules. They were also more likely to have received previous treatment with DMARDs (in particular, intramuscular gold, D-penicilla-
\end{abstract}

Table 1 Demographic characteristics and clinical variables of patients with rheumatoid vasculitis ( $R V$ cases) and rheumatoid arthritis ( $R A$ controls)

\begin{tabular}{lcc}
\hline & $\begin{array}{c}R V \text { cases } \\
(n=69)\end{array}$ & $\begin{array}{c}R A \text { controls } \\
(n=138)\end{array}$ \\
\hline Age (years) & $66(31-82)$ & $65(22-88)$ \\
Male gender & $32(46)$ & $38(28)^{\star \star}$ \\
RA duration (years) & $12(0-52)$ & $10(0-46)$ \\
Patients with rheumatoid factor ever & $69(100)$ & $111(80)^{\star \star}$ \\
Patients with joint erosions & $66(96)$ & $113(82)^{\star \star}$ \\
Patients with subcutaneous nodules ever & $47(68)$ & $55(40)^{\star \star}$ \\
DMARDs ever usedt & $2 \cdot 2(0-7)$ & $1 \cdot 6(0-6)^{\star}$ \\
DMARDs ever used per year & $0 \cdot 27$ & $0 \cdot 22$ \\
Patients ever treated with: & $53(77)$ & $105(76)$ \\
Antimalarials & $43(62)$ & $62(45)^{\star}$ \\
Intramuscular gold & $28(41)$ & $26(19)^{\star \star}$ \\
D-penicillamine & $7(10)$ & $6(4)$ \\
Sulphasalazine & $14(20)$ & $9(7)^{\star \star}$ \\
Azathioprine & $5(7)$ & $6(4)$ \\
Methotrexate & $1(1)$ & 0 \\
Cyclophosphamide & $2(3)$ & $2(1)$ \\
Cyclosporine & $3(4)$ & $3(2)$ \\
Oral gold & $16(23)$ & $21(15)$ \\
Corticosteroids & & \\
Patients with extra-articular features ever as scored & $13(19)$ & $8(6)^{\star \star}$ \\
one year before the index date§ & $3(4)$ & $2(1)$ \\
Nail fold lesions & $7(10)$ & $3(2)^{\star \star}$ \\
Pericarditis & $2(3)$ & 0 \\
Pleuritis & $2(3)$ & 0 \\
(Epi)scleritis & $2(3)$ & $1(1)$ \\
Distal sensory neuropathy & & \\
Felty's syndrome & & \\
\hline
\end{tabular}

Values are median (range), number (\%), or tnumber (range)

IIndex date = time that RV was diagnosed in the case or the corresponding date in the RA control.

Differences between RV cases and RA controls: ${ }^{\star} p<0.05$; ${ }^{\star \star} p<0.011$. mine, and azathioprine), and to have had extra-articular features scored one year before the index date (table 1).

At the time of diagnosis, the most common extra-articular features of $\mathrm{RV}$ cases were petechiae or purpura $(56 \%)$, nail fold lesions $(41 \%)$, deep skin ulcers $(29 \%)$, distal sensory neuropathy $(20 \%)$, (epi)scleritis $(13 \%)$, mononeuritis multiplex $(12 \%)$, pleuritis $(7 \%)$, gangrene $(6 \%)$, pericarditis $(4 \%)$, Felty's syndrome $(3 \%)$, and ischaemic bowel disease $(1 \%)$. In RA controls, no such extra-articular features were observed except for pleuritis $(0.7 \%)$ and Felty's syndrome $(0.7 \%)$. Compared with RA controls, RV cases were treated more frequently with azathioprine $(15 \% v$ $3 \%, \mathrm{p}<0.01)$, D-penicillamine $(12 \% v 3 \%$, $\mathrm{p}<0.05)$, or corticosteroids $(19 \%$ v $6 \%$, $\mathrm{p}<0.05)$. For the other DMARDs, no significant differences were observed.

Table 2 presents the crude and adjusted risk estimates of the variables potentially associated with RV. The variables that were associated with the development of RV after adjustment for all other variables were, in order of strength: increased concentrations of RF, joint erosions, treatment ever with D-penicillamine, nail fold lesions, the presence of any of the other extraarticular features, the presence of subcutaneous nodules, male gender, number of DMARDs previously prescribed, and treatment ever with azathioprine. In a second analysis, in which the variables of the treatment regimens as scored cumulatively up to the index date were replaced by the variables of the treatment regimens as documented at the index date, only the association between RV and the treatment with corticosteroid altered: corticosteroid treatment at the index date was found to be associated with the development of $\mathrm{RV}$.

\section{Discussion}

This controlled study confirmed the findings of previous uncontrolled studies suggesting associations of $\mathrm{RV}$ with male gender, the presence of increased concentrations of RF, and extra-articular features. ${ }^{1-5}$ The strongest association was found for increased serum concentrations of RF. In addition, association with the development of RV was found for the number of DMARDs previously prescribed, treatment ever with D-penicillamine or azathioprine, and treatment with corticosteroids at the time of diagnosis of RV.

The reason for the male predominance remains unexplained, though smoking habit, which is associated with male gender, has been suggested as a possible explanation. ${ }^{9}$

The association between RF and the development of RV may be explained by the role of immune complex formation. High titres of $\mathrm{RF}$, invariably found in patients with $\mathrm{RV},{ }^{10}$ lead to the formation of immune complexes. ${ }^{11}$ The reported association between concentrations of circulating immune complexes and vascular lesions in the skin of patients with RV indicates that deposition of immune complexes in the vessel wall leads to RV. ${ }^{12}$ 
Table 2 Crude and adjusted $\dagger$ odds ratios (OR) with 95\% confidence interval (95\% CI) of selected variables potentially associated with the development of rheumatoid vasculitis $(R V)$ in $R V$ patients $(n=69)$ compared with $R A$ patients not suspected to have $R V(n=138)$

\begin{tabular}{|c|c|c|}
\hline & $\begin{array}{l}\text { Crude OR } \\
(95 \% C I)\end{array}$ & $\begin{array}{l}\text { Adjusted }+O R \\
(95 \% C I)\end{array}$ \\
\hline Age (years) & $1.01(0.99$ to 1.04$)$ & $1.02(0.99$ to 1.06$)$ \\
\hline Male gender & $2.29(1.24$ to 4.23$)$ & $2.33(1.02$ to 5.33$)$ \\
\hline RA duration (years) & $1.02(0.99$ to 1.05$)$ & $1.00(0.96$ to 1.05$)$ \\
\hline Rheumatoid factor $(+/-)$ & $17 \cdot 74(2 \cdot 34$ to $134 \cdot 6)$ & $9.58(0.99$ to 91.94$)$ \\
\hline Joint erosions $(+/-)$ & $5.58(1.58$ to 19.67$)$ & $5.02(0.86$ to 29.21$)$ \\
\hline Subcutaneous nodules $(+/-)$ & $3.39(1.76$ to 6.51$)$ & $2.39(1.05$ to 5.70$)$ \\
\hline Nail fold lesions ${ }^{\star}(+/-)$ & $3.53(1.40$ to 8.89$)$ & $3.00(0.64$ to 14.11$)$ \\
\hline $\begin{array}{l}\text { Extra-articular features } ₫ \text { other than subcutaneous nodules } \\
\text { or nailfold lesions }{ }^{\star}(+/-)\end{array}$ & $5 \cdot 50(1.75$ to $17 \cdot 27)$ & $2.69(0.55$ to 13.20$)$ \\
\hline No. of previously prescribed DMARDs & $2.78(0.81$ to 9.47$)$ & $2 \cdot 10(0 \cdot 29$ to $15 \cdot 18)$ \\
\hline Ever intramuscular gold treatment $(+/-)$ & $2 \cdot 04(1 \cdot 12$ to $3 \cdot 70)$ & $0.90(0.38$ to $2 \cdot 17)$ \\
\hline Ever azathioprine treatment $(+/-)$ & $4.00(1.52$ to 10.56$)$ & $1.92(0.43$ to 8.65$)$ \\
\hline Ever D-penicillamine treatment $(+/-)$ & $4.73(1.99$ to 11.23$)$ & $3.36(0.96$ to 11.79$)$ \\
\hline Ever corticosteroid treatment $(+/-)$ & $1.59(0.80$ to $3 \cdot 15)$ & $0.89(0.30$ to $2 \cdot 68)$ \\
\hline$\cdots \cdots \cdots-\cdots,-\cdots,-\cdots,-\cdots$ & $---\cdots---\cdots$ & $---\cdots-\cdots$ \\
\hline Intramuscular gold treatment at the index date $\ddagger(+/-)$ & $0.44(0.12$ to 1.60$)$ & $0.29(0.06$ to 1.40$)$ \\
\hline Azathioprine treatment at the index date $(+1-)$ & $5.00(1.57$ to 15.94$)$ & $1.80(0.34$ to 9.42$)$ \\
\hline D-penicillamine treatment at the index date $f(+/-)$ & $4.88(1.28$ to 18.60$)$ & $6.15(1.02$ to 36.89$)$ \\
\hline Corticosteroid treatment at the index date $\neq(+/-)$ & $3.25(1.35$ to $7 \cdot 84)$ & $5.85(1.33$ to 25.62$)$ \\
\hline
\end{tabular}

fOR adjusted for all variables as scored at the index date, except for ${ }^{\star}$ extra-articular features indicated, which were scored positive only when present up to one year before the index date.

Pericarditis, pleuritis, (epi)scleritis, distal sensory polyneuropathy, and Felty's syndrome.

fOR adjusted for all other variables, except the variables of treatment regimens above the dashed line.

$+/-=$ Present or absent.

The association of RV with subcutaneous nodules and nail fold lesions preceding the development of RV cannot be explained on the grounds that these lesions are a direct expression of vasculitis. These lesions are characterised histologically by perivascular mononuclear cells and intimal proliferation with intravascular thrombosis 1 -features that do not fulfill the established criteria for vasculitis. ${ }^{13}$ However, the strong association found between the development of RV and subcutaneous nodules, in addition to nail fold lesions one year before the diagnosis of RV, provides additional support for the view that these lesions may be part of the disease spectrum of RV. The same may be true for other extra-articular features, such as serositis.

The association between $\mathrm{RV}$ and the number of DMARDs previously prescribed suggests that $\mathrm{RV}$ is a disease manifestation that marks the most severe spectrum of RA, rather than a separate disease entity. This hypothesis is supported by the association found between RV and indicators of a severe disease outcome-the presence of joint erosions, ${ }^{14}$ subcutaneous nodules, and increased concentrations of RF. ${ }^{15}$ The concept of $\mathrm{RV}$ as a marker of severe RA implies that the pathogenetic mechanisms underlying $\mathrm{RV}$ are related to those that are specific for RA. The association found in the present study between D-penicillamine or azathioprine treatment and the development of $\mathrm{RV}$ is probably attributable to the fact that, in our centre, D-penicillamine and azathioprine are started late in the course of RA, after the failure of other DMARDs, and may be explained further by considering D-penicillamine and azathioprine as markers of a severe course of RA.

Treatment with corticosteroids has been suggested by some authors to be associated with the development of $\mathrm{RV},{ }^{7}$ though others have pointed out that seriously ill patients who develop vasculitis are likely to be treated with corticosteroids. $^{1}$ The latter observation is supported by the results of the present study, in which an association was found between the development of RV and corticosteroid treatment at the time of diagnosis, but not with ever having received corticosteroid treatment.

The study was supported by a grant from Het Nationaal Reumafonds. We are grateful to C Bakker, M Polderman, $\mathrm{V}$ de Vries, and $\mathrm{N}$ Warmenhoven for their help in reviewing the medical charts.

1 Bywaters E G L, Scott J T. The natural history of vascular lesions in rheumatoid arthritis. $\mathcal{f}$ Chron Dis 1963; 16: 905-14.

2 Wilkinson $\mathrm{M}$, Torrance $\mathrm{W} \mathrm{N}$. Clinical background of rheumatoid vascular disease. Ann Rheum Dis 1967; 26: $475-80$.

3 Scott D G I, Bacon P A, Tribe C R. Systemic rheumatoid vasculitis: a clinical and laboratory study of 50 cases. Medicine 1981; 60: 288-97.

4 Vollertsen R S, Conn D L, Ballard D J, Ilstrup D M, Kazmar R E, Silverfield J C. Rheumatoid vasculitis: Kazmar $\mathrm{R}$ E, Silverfield J C. Rheumatoid vasculitis: survival

5 Watts R A, Carruthers D M, Symmons D P M, Scott D G I. The incidence of rheumatoid vasculitis in the Norwich Health Authority. $B r \mathcal{F}$ Rheumatol 1994; 33: $832-3$

6 Westedt M L, Breedveld F C, Schreuder G M T, D'Amaro J, Cats A, de Vries R R P. Immunogenetical heterogeneity of rheumatoid arthritis. Ann Rheum Dis 1986; 45: $534-8$.

7 Johnson R L, Smyth C J, Holt G W, Lubchenco A, Valentine E. Steroid therapy and vascular lesions in rheumatoid arthritis. Arthritis Rheum 1959; 2: 224-49.

8 Ropes R W, Bennett G A, Cobb S, Jacox R, Jessar R A. 1958 revision of diagnostic criteria for rheumatoid arthritis. Arthritis Rheum 1959; 2: 16-20.

9 Struthers G R, Scott D L, Delamere J P, Sheppard H, Kitt M. Smoking habits and rheumatoid vasculitis. Rheumatol Int 1981; 1: 145-6.

10 Theofilopoulos A, Burtonboy G, Lopalluto J J, Ziff M. IgG rheumatoid factor and low molecular weight IgM Arthritis Rheum 1974; 17: 272-84.

11 Pope R M, Yoshinoya S, McDuffy S. Detection of immune complexes and their relationship to rheumatoid factor in a variety of autoimmune disorders. Clin Exp Immunol 1981; 46: 259-67.

12 Westedt M L, Meijer C J L M, Vermeer B J, Cats A, de Vries E. Rheumatoid arthritis. The clinical significance de Vries E. Rheumatoid arthritis. The clinical significance of histo- and immunopathological abno

13 Lie J T. Illustrated histopathologic classification criteria for selected vasculitis syndromes. Arthritis Rheum 1990; 33: selected

14 Heijde van der D M F M, van Riel P C L M, van Leeuwen $M A$, van 't Hof $M$ A, van Rijswijk M H, van de Putte L B A. Prognostic factors for radiographic joint damage and physical disability in early rheumatoid arthritis. A prospective follow-up study in 147 patients. $\mathrm{Br} F$ Rheumatol 1992; 31: 519-25.

15 Zeben van D, Hazes J M W, Zwinderman A H, Vandenbroucke J P, Breedveld F C. Factors predicting outcome of rheumatoid arthritis: results of a follow-up study. F Rheumatol 1993; 20: 1288-96. 